\title{
On the Application of Modern Comics Formal Language and Digital
}

\section{Media Technology in Traditional Comics}

\author{
Jin-dong Wang \\ Fijian Jiangxia University, Fuzhou350002, China. \\ wjdpm2008@163.com
}

Key words: traditional comics, modern comics, digital media technology.

\begin{abstract}
Traditional comics, as popular books loved by the masses, have gained great achievement and status in the art history of New China, which surpass any forms of art and contain abundant social and cultural connotation as well as high artistic value. From the beginning of 1990s, traditional comics are shrinking rapidly till its disappearance from book market, which forms a sharp contrast to the vigor and vitality of modern comics. This journal focuses on exploring the future development mode of traditional comics from three aspects--- the decline of traditional comics, advantages of modern comics and the application of digital media technology, which is of great significance to upholding traditional culture of our nation and the development innovation of traditional Chinese comics in the new era of media.
\end{abstract}

\section{Introduction}

Traditional comics, also known as picture-story books, are an art form that tells stories with continuous pictures. The picture and its accompanying essay are both excellent and easy to understand, which has become the important food for human minds before 1990s and reflects social and cultural patterns in a special historical period. Traditional comics have gone through bumpy and dramatic changes, which deserve a sad sigh. They first appear as vulgar readings for human entertainment before Liberation, then after Liberation as popular books to equip people with science and culture knowledge, and now they have become collection of lovers. It is worth questioning why traditional comics have suffered such a fate turn? This journal will discuss how to take innovation on former development mode and make readers take interest in traditional comics again from the following three aspects.

\section{Reasons for the Decline of Traditional Comics}

\subsection{Lack of Originality and Subject Repetition}

At the beginning of New China, people's cultural level is generally not high. Our nation has attached great importance to the popularity and education of comics. Comics in New China bear the responsibility in the construction of people's cognition in shaping history and outlines the new nation quality in shaping spirit, leading to the constraint in content and time urgency[1]. Therefore, comics about adaption from classic literary works as well as comics revealing contemporary struggles and life come into being. The content and subject of comics depend too much on limited classic literary works, leading to the repetition of publications. There are five publishing houses on "Huo Yuanjia" in a total number of 28 million volumes. Besides, there are more than ten publishing houses on "Legend of Chen Zhen"[2]. 


\subsection{Rough Manufactures and Formality Pursuit}

Comics boost in 1980s and the circulation has been on a rise. some publishing houses openly demand speed but quality. Painters are paid highest remuneration without starting to draw when the literary scripts are given to them. Meanwhile, the spread of martial arts makes painters constantly on the run. They usually receive the next script without finishing the one on hands. Some painters begin to less treasure art and carry out their ideas irrespective of external circumstances[3]. There are even comics that are published directly from movie or TV series remakes, which cannot reach the proper clarity, not to mention character and scene designing. From the beginning of 1980s, the artistic expression of comics has become increasingly rich and colorful. Although the expression enhances artistic appeals, the unconventional formality pursuit ignores the readers aesthetic levels and reading needs.

\subsection{Single Layout Form}

Traditional comics creation starts from the literary text scripts, then the painter equip text scripts with pictures. Text is the content guidance of pictures while pictures are the image representation of the text. The most basic form of layout is pictures above text or on the left of the text. Each painting can only display the moment of the story, while the development of plot is driven largely by text scripts, coupled with static layout and format, which results in the lack of comic coherence , along with dull and single visual views and slow rhythm.

In conclusion, once modern comics that have various themes and strong visual impact come into market, traditional comics market space will be taken up and vanish from the market in less than ten years.

\section{Lessons from Modern Comics Formal Language}

\subsection{Techniques of Visual Expression}

For starters, modern comics visualized invisible elements such as sounds, emotions and speed. For instance, the dialogue and sounds in the story appear as different dialogs with onomatopoeias; speed and action appear as different lines to express characters movement track; anger appears as smoke above heads, speechlessness as sweat drops and shyness as slashes. This visualized method undoubtedlystrengthens visual effect of scenes.

Secondly, Modern comics introduce movie scenes so that static pictures become coherent, dynamic, more complete and vivid. As the plot develops, the scene is also scheduled and changed. This transformation greatly enriches the expressions of modern comics, enhances the visual appeal so that readers feel like watching real movies. Let's take the new comics "JUVENILE REMIX" as an example. The author take extensive scene scheduling and spot changing instead of single and dull medium composition to strengthen the narrative effect. Transformation from close-up to panorama, medium and close shot, as well as the scheduling of up and down position, shot and reverse shot, fade in and fade out shots, makes a coherent and dynamic visual experience. These multi-shots and multi-positions are obviously more powerful than plain narration.

\subsection{Originality}

Due to the constraints of the domestic political environment at that time, the content and subject creation of traditional comics start with a clear political intention, with moral criterion and education as the key to political service, which requires the theme and content of comics must be in line with the political purpose of literary works, fable stories and biographies for adaptation, resulting in rigid comic themes, empty content and strong preaching. In that case, the dull content cannot appeal to readers of different ages and levels.

Comic master He Youzhi once says:" why can cartoons easily defeat our comics? In a word, our 
comics lack originality"[4]. Originality is the soul of any artistic creation. The reason why modern comics have maintained a certain position and appeal is they have kept the originality. The famous Japanese manga Detective Canon chooses detective stories as its theme, telling how Kudou Shinichi solves detection cases. The story is interspersed with a number of scientific knowledge, survival skills, history and culture, such as the way to escape various accidents, the nature and use of different chemicals, the construction and operation of aircraft and ship. Readers can not only seize scientific knowledge while reading, but can train their logical thinking and reasoning ability through these cases. As the plot develops, readers will catch the geographical features as well as history and culture in different places. Such a fantastic and bizarre modern comic is bound to attract readers, especially teenagers who are full of curiosity and imagination.

\subsection{Montage Narrative Skills}

He Youzhi defines the nature of comics as narration. Comics are to draw pictures and the job for drawing is to present stories[5]. Traditional comics adopt "sequential narration" in order to achieve narrative effect and become more easily understood by people, which is also the most common and simple narrative method. When a more complex and tortuous plot needs to be presented, the method above cannot work well. Montage narrative approaches are necessary such as interspersed narration, flashbacks and parallel narration. American comics JIMMY CORRIGAN is a typical Montage work which is so far the only one to seize the First Book Award. This comic adopts multi-storylines narrative method, and the plot has two main storylines. Jimmy Corrigan is raised by a single mother. He is a lost man who has poor communication and wretches appearance in the 1980s. The other line takes place about 100 years ago when Jimmy's grandfather James is a 9-year-old boy. They both grow up as orphans and their experiences are quite alike. This is a sad story among four generations like a fate circle. Every time readers read, they will sense many spiritual shocks. Besides, the uses of Montage make readers feel like watching a sad film. Another example of Montage is JUVENILE REMIX. The author disrupts the normal time sequence and adopts flashback interspersed and other parallel narration to present its ending. The flexible Montage narrative methods in modern comics surpass the dull and straightforward narration in traditional comics. Readers can sense the plot development in a all-round and three-dimensional way.

\section{The Combination of Traditional Comics and Digital Media Technology}

With the continuous development of digital media technology, the "action", "sound", and "special effects" of traditional comics can be seen, heard and sensed.The impact that digital media technology brings about has stemmed into every aspects of people's lives. It has gradually developed into a new audio-visual art form such as various popular dynamic expressions and GIF images in internet chatting. The reason why dynamic images receive welcome is they can express people's mood and emotion with rich audio-visual forms and meet their demands of conveying messages swiftly, conveniently and inexpensively. Therefore, comics combined with digital media technology have an obvious advantage.

\subsection{More Rapid Circulation and Wider Range}

In traditional paper-media era, the spread method of traditional comics is quite single, mainly in paper books and periodicals, and the scale and range are also limited. With the rapid development of network technology and he popularity of computers, mobile phones and other electronic products, digital media technology has become a vital means of conveying message. People are free to download their favorite eBooks by using smart phones, computers and we-media platforms. Besides, they can freely watch and read at home, in outdoors, on buses and subways, even in shopping malls. The circulation speed and range are superior to traditional printing media. At the same time, digital 
media comics have lowered the standard for comic makers, making more young artists and amateurs disseminate their works through internet, smart phones, computers and other we-media platforms.

\subsection{Convenient Storage VS No Transportation VS Good Strength}

Traditional comics are made from paper. No matter how dedicatedly they are protected, paper turns yellow and gets rotten with time passing. However, digital media comics do not encounter these problems. They can be swiftly and massively stored for a long period through Internet, smart phones and computers. Besides, they don't charge high fees as traditional comics do. Modern digital comics can hardly be out of stock, short of supply or out of print, which save manpower, material and financial resources and repeated production process.

\subsection{Rich Visual Form and Regenerated Way of Reading}

Digital media technology provides comic artists with new creation techniques and breaks through traditional comics creation concept. Boundaries between traditional static comics and animation are broken, Digital media technology makes static and flat strips become stereo and dynamicand subverts traditional comics visual patterns and way of reading, presenting traditional comics in a new art form. It not only enhances the readability and interest in comics, bring unprecedented visual experience to readers, but allows readers to hear and touch the specific picture effect and story plot, undoubtedly more attracting readers.

The combination of digital media technology and traditional comics not only inherit the characteristics of better illustrations and words, but also show up sound, action, and special effects. The new comicart style extends the space of text description and provides a more specific, more intuitive, more abundant picture effect than traditional single graphic comics, promoting new comic art forms and varieties,making a new reading experience for readers and enhancing the appeal of the comic art.

\section{Conclusion}

With the coming of new media era, especially the individual centered we-media coming towards mainstream, traditional comics should seize the opportunity to bold innovation through the formal language in modern comics to enrich the traditional comics single formal language. By combining digital media technology, sound, action, special effects and other abstract elements in comics will be expressed by digital media technology, which makes comics into a set of visual, auditory and tactile art form. Readers can both experience traditional comics characteristics and enjoy a new visual effect, contributing to the conversion of digitalization development mode in traditional comics. In summary, the reform and innovation of traditional comics not only involve their future development, but having a practical significance on the inheritance and innovation of traditional Chinese culture.

\section{References}

[1] Fei Wenming, 20th Century Researches on Chinese Comics Narration,J. Suzhou Art and Design Technology Institute Studies, 2012,3.

[2] Jiang Weipu, Comics should not forsake good for the sake of gold,N. China Youth Daily, $1985,6,30$.

[3] Jiang Weipu, Comics should not forsake good for the sake of gold,N. China Youth Daily, 1985,6,30.

[4]Oral Factual Records: Back to the Scene of Comics, The Art World(2002).

[5] Xu Jian,Unstoppable Extension Lines--- Interview of He Youzhi,J. Artists, 2003. 